\title{
Johnson Noise and Optical Characteristics of Polymer Nanocomposites based on Colloidal Quantum Dots and in-situ Nanoparticles Formation
}

\author{
Fatin Hana Naning ${ }^{*}, 1$, S. Malik ${ }^{2}$, Lee Feng Koo ${ }^{1}$, Tze Jin Wong ${ }^{1}$, Pang Hung Yiu ${ }^{1}$ \\ ${ }^{1}$ Department of Basic Science and Engineering, Faculty of Agriculture and Food Sciences, Universiti Putra Malaysia Bintulu \\ Campus, 97008 Bintulu, Sarawak, 93010, Malaysia \\ ${ }^{2}$ Physics Department, Faculty of Science, Universiti Pendidikan Sultan Idris, 35900 Tanjong Malim, Perak, 31400 , Malaysia
}

\begin{tabular}{l} 
A R T I C L E I N F O \\
\hline Article history: \\
Received:10 August, 2020 \\
Accepted: 11 September, 2020 \\
Online: 12 October, 2020 \\
\hline
\end{tabular}

Keywords:

Johnson Noise

Polymer Nanocomposite

Cadmium sulfide

\begin{abstract}
A B S T R A C T
Electrical and optical properties of polymer nanocomposite thin films have been analyzed to study their reliability and competency as a component for optoelectronic devices such as LED and solar cells. Polymer nanocomposite encounters various challenges, such as the dispersion of nanoparticles in the matrix that hinders their efficiency for potential devices. In this paper, two types of polymer nanocomposites have been fabricated, and their Johnson noise, current density-voltage, and optical have been measured. The first type of nanocomposite produced through an in-situ method, that is by impregnating CdS or CdSe nanoparticles in conjugated polymer, P3HT (NP-CdX:P3HT). The nucleation of the nanoparticles was done using gas exposure. The second type is by directly adding $C d S$ or $C d S$ e quantum dots into P3HT (QD-CdX:P3HT). Both kinds of polymer nanocomposite thin films were fabricated using modified Langmuir-Blodgett technique. Results showed that for frequency above $10 \mathrm{~Hz}$, the Johnson noise was less than $1 \times 10^{-27} \mathrm{A2} / \mathrm{Hz}$, regardless of the quantity of quantum dots or nanoparticles. The J-V results show (NP-CdX:P3HT) electrical performance compared with QD-CdX:P3HT. High polymer crystallization of NP$C d X: P 3 H T$ thin films is revealed by $U V$-Vis absorbance spectra. The quantum confinement effect is evidence through peak shifting and depreciation of absorption. The photoluminescence intensity of thin films decreased when they were exposed to the gas. It can be concluded that the NP-CdX:P3HT nanocomposites can be further studied as they have greater potential to be exploited in optoelectronic devices.
\end{abstract}

\section{Introduction}

Polymer nanocomposites can be prepared through various methods, including physical adsorption, ligand-metal interaction, or by blending nanoparticles with the desired polymers. The inability of nanoparticles to spread uniformly in matrices is one of the key obstacles in the development of polymer nanocomposites for optoelectronic devices. Besides the size of the nanomaterials, the degree of mixing of the materials influences the polymer nanocomposites characteristics. If the nanomaterials are poorly dispersed, the mechanical properties of the thin films may degrade [1]. The nanomaterials blend affects the movement of electrons and the transport of holes. Current and holes motion cause excess

*Corresponding Author: Fatin Hana Naning, UPM Bintulu Sarawak Campus, fatinhanaz@upm.edu.my noise in all conducting materials. Various types of electrical noises are present in an electronic system such as Johnson noise, $1 / f$ noise, and generation-combination noise.

Johnson noise, also referred to as thermal noise, is caused by the movement of electrons in a material that produces a fluctuating electromotive force (emf) [2]. The electron scattering creates noise in terms of small net current flow. As the temperature and resistance of the material increases, the noise increases as well.

Johnson noise theory derived by Johnson and Nyquist by stating

$$
S_{V}(f)=4 k R h f N(f, T)
$$


where $S_{V}(f)$ is the power spectral density (PSD) of the voltage noise, $k$ is Boltzmann constant, $R$ is the resistance, $h$ is Planck constant, and $f$ is the frequency. $N(f, T)$ is Planck number representing the energy quanta $h f$, at frequency $f$ and temperature, $T[3,4]$. It can also be expressed as,

$$
N(f, T)=k T / h f
$$

The noise-voltage power spectral density under open-circuit condition is given by

$$
S_{V}(f)=4 k^{2} T R
$$

Alternatively, the noise-current power spectral density $S_{I}(f)$ can be calculated using

$$
S_{I}(f)=4 k^{2} T / R
$$

Equations (3) and (4) valid for frequency below tens of gigahertz over a wide range of temperatures [5].

Johnson noise arises from the random motion of free electrons that leads to temporary electrons agglomeration and voltage fluctuation [6]. The noise can be estimated by analysing the power spectral density (PSD) obtained from low-frequency electrical noise measurement. It is a conventional technique used to study the reliability and quality of electronic devices as the procedure is able to differentiate failed devices. Usually, the impaired devices hold excess noise [7] because PSD of noise increases with stress and damage [8]. Deterioration process of Organic Light Emitting Diode (OLED) utilizing noise measurement has been studied by Rocha et al. and Carbone $[9,10]$. Both concluded that noise increases with damage level. Another research group reports that the intrinsic transport mechanism greatly influences lowfrequency noise [11].

Polymer nanocomposites are commonly prepared by mixing the polymer with the nanomaterials through various tedious steps. The small introduction of nanomaterials into conjugated polymer matrices causes the modification in the polymers' properties due to the substantial surface-area-to-volume ratio of nanoparticles [12]. Researches showed that mechanical and optical properties of the polymer were altered as well $[13,14]$.

However, this method has some drawbacks that hamper the efficiency of the thin film due to the presence of ligand that inhibits charge transfer. Furthermore, the usage of cosolvent to mix the nanomaterials and polymer negatively affect the orientation of the polymer [15]. One way to impede these issues is by growing the nanomaterials in-situ in the matrices.

In the present study, we used poly(3-hyexylthiophene) (P3HT) as the polymer matrix, and the nanomaterials were cadmium sulfide (CdS) and cadmium selenide (CdSe). The nanocomposites were prepared by directly adding $\mathrm{CdS}$ or CdSe quantum dots (QD$\mathrm{CdX}: \mathrm{P} 3 \mathrm{HT}$ ) into P3HT, or by impregnating $\mathrm{CdS} / \mathrm{CdSe}$ nanoparticles in the polymer matrix in-situ (NP-CdX:P3HT).

Poly(3-hyexylthiophene) is one of the well-studied conjugated polymers. It possesses a relatively strong absorption coefficient, low energy band gap, consequently high absorption even in very thin films [16]. P3HT also has greater hole mobility as compared to poly(phenylene vinylene) (PPV), another material that widely used for solar cells and LED [17]. P3HT is based on thiophene rings (four carbon atoms and one sulfur) and highly soluble in common organic solvents. Studies showed that regio-regular P3HT (rr-P3HT) has a higher degree of polymer chain ordering and electrical conductivity as compared with regio-random P3HT (rra-P3HT) $[18,19]$. The CdS and CdSe were chosen because they possess lower HOMO (Highest Occupied Molecular Orbital) and LUMO (Lowest Unoccupied Molecular Orbital) than that of poly(3-hexylthiophene) [20].

The computation of Johnson noise engaged low-frequency electrical noise measurement (LFeNM), and the analysis was done at $25{ }^{\circ} \mathrm{C}$. LFeNM is a method generally employed to verify the reliability of any electronic devices. The relationship of Johnson noise to $J-V$ and optical characteristics will be discussed as well.

\section{Experimental Setup}

This research involved four types of polymer nanocomposite thin film. The films were composed of II-VI semiconducting materials, $\mathrm{CdX}$ (CdS or CdSe), and conjugated polymer Poly(3hexylthiophene) (P3HT).

\subsection{Materials and Sample Preparation}

Modified Langmuir-Blodgett method has been adopted to fabricate two types of thin films. The first type is the in-situ method, made by nucleating cadmium sulfide (CdS) and cadmium selenide $(\mathrm{CdSe})$ nanoparticles (NP) directly in the P3HT matrice (NP-CdS:P3HT and NP-CdSe:P3HT). The second type of thin film was made by adding CdS and CdSe quantum dots (QDs) into P3HT (QD-CdS:P3HT and QD-CdSe:P3HT). Before these QDs were incorporated into $\mathrm{P} 3 \mathrm{HT}$, they were treated by refluxing them for 15 minutes in hexanoic acid at $115{ }^{\circ} \mathrm{C}$ to remove trioctylphosphine oxide (TOPO) that capped the QDs. All materials were purchased from Sigma Aldrich. The solvent used to dissolve P3HT and stearic acid is chloroform (Mallinckrodt). The substrates used were ITO coated glass $(5 \Omega / \mathrm{sq})$ from Nanocs. ITO coated glass also acts as an electrode for electrical characterization. All materials used were as-received unless stated otherwise.

The first type of nanocomposite, NP-CdX:P3HT thin films were prepared by dispensing $0.4 \mathrm{ml}$ P3HT solution $(0.2 \mathrm{~g} / \mathrm{l})$ and 0.1 stearic acid solution $(0.14 \mathrm{~g} / \mathrm{l})$ on water subphase that contained $0.5 \mathrm{mM}$ cadmium (II) chloride $\left(\mathrm{CdCl}_{2}\right)$. Stearic acid possesses amphiphilic properties; hence it acts as a stabilizer to P3HT because P3HT is a non-amphiphilic material, thus not suitable for LB deposition. The stearic acid mixture will lessen the domination of the hydrophobic part of P3HT, and reduce the likelihood of supermonolayer structures formation. It also functioned as a capping agent of a divalent cation, cadmium ion, into its headgroup structure $(\mathrm{COOH})$.

The films were deposited when the Langmuir layer surface pressure is continuously at $27 \mathrm{mN} / \mathrm{m}$ at an angle of $45^{\circ}$. The modified LB technique allows us to construct large-area polymeric thin films in a controlled order. After every deposition, each transferred layer was put in the oven for $15 \mathrm{~s}$ to dry the film and induce cross-linking in the polymer. The temperature of the oven was $50^{\circ} \mathrm{C}$. Thirteen layers of film $(\sim 20 \mathrm{~nm})$ were deposited on the ITO coated glass substrate. After the last film was transferred and 
dried, the film was put in the chamber of hydrogen sulfide $\left(\mathrm{H}_{2} \mathrm{~S}\right)$, or hydrogen selenide $\left(\mathrm{H}_{2} \mathrm{Se}\right)$ for 6 hours. This process was done to nucleate nanoparticles - $\mathrm{CdS}$ or $\mathrm{CdSe}$, within polymer layers. Finally, the exposed films were annealed for 10 minutes in an oven at $120^{\circ} \mathrm{C}$.

The second type of nanocomposite, QD-CdX-P3HT thin films, the QDs were added at $25 \mathrm{wt} \%$ or $50 \mathrm{wt} \%$ of P3HT solution $(0.2$ $\mathrm{mg} / \mathrm{ml})$. The solution was then carefully injected onto the surface of water subphase. Solid-phase optimized for the film $17 \mathrm{mN} / \mathrm{m}$. Similar to the in-situ method, thirteen layers of film were deposited and dried. However, immediately after the last transfer, the film was straight put into an oven for annealing process. All samples were prepared in the cleanroom ISO 6 environment. Samples that will be tested for electrical characteristics were deposited with 150 $\mathrm{nm}$ of aluminum layer that serves as an electrode.

\subsection{Measurement}

Johnson noise measurement utilized current-to-voltage lownoise/low input impedance preamplifier (Signal Discovery), 35670A Dynamic Signal Analyser (Agilent). An interference shield box was used to encase the specimen in order to protect them from external wave or oscillation. The gain of the measurement has been set at $10^{-8}$ low noise (LN). The low-level noise signal measured from the sample was then fed to an amplifier, which converts the current power $\left(\mathrm{A}^{2}\right)$ to voltage power $\left(\mathrm{V}^{2}\right)$. The amplifier output would later become the DSA input and processed using LabView. The noise current power spectral density, $S I(f)$, was evaluated within the $10 \mathrm{~Hz}$ to $1000 \mathrm{~Hz}$ frequency range. The noise reading was repeated 200 times.

(a)

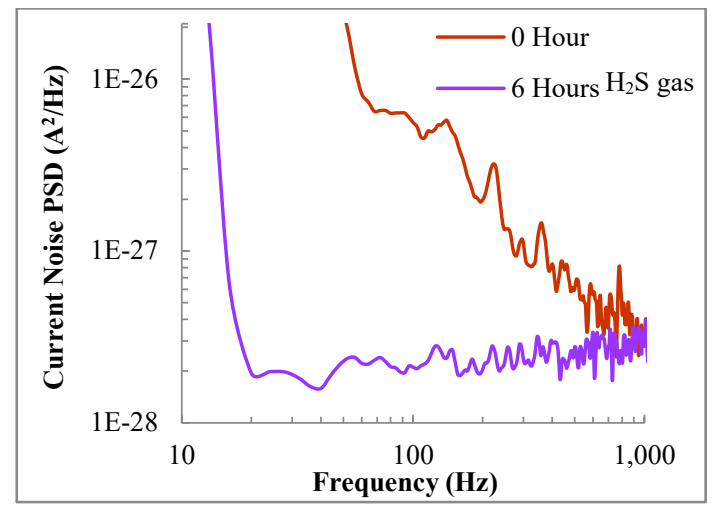

(c)

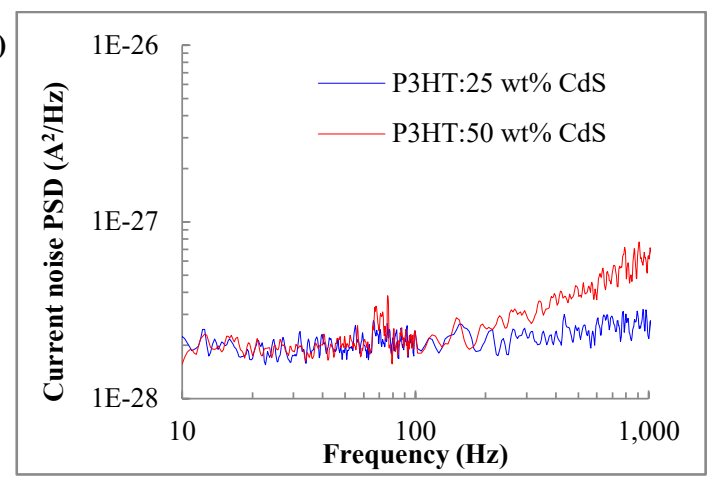

Keithley 2636A source measure unit (SMU) was used to measure current density-voltage $(J-V)$ characteristics. The SMU was attached to a four-point probe and a solar simulator with a light density of $100 \mathrm{~mW} / \mathrm{cm}^{2}$ that complies with the AM $1.5 \mathrm{G}$ spectrum. The measurement was carried out by continuously sweeping the feed voltage from -1.5 to $+1.5 \mathrm{~V}$.

The spectral absorption measurements were performed using JASCO V570 UV-Vis (Ultraviolet-visible) spectrophotometer operated at a resolution of $1 \mathrm{~nm}$. Perkin Elmer LS 55 Fluorescence Spectroscopy was used to study the PL characteristic of the samples. The samples were excited at $430 \mathrm{~nm}$, and the excitation slit was set at $10 \mathrm{~nm}$, while the laser emission slit was $15 \mathrm{~nm}$. Scan speed was $500 \mathrm{~mm} / \mathrm{min}$. The parameters were determined by optimizing the value of a reference sample.

\section{Results and Discussion}

Figure 1 (a) and (b) show the Johnson noise of NP-CdS:P3HT and NP-CdSe:P3HT, respectively. The unexposed film has the greatest resistance expressed as the highest noise level compared to the films exposed to $\mathrm{H}_{2} \mathrm{~S}$ or $\mathrm{H}_{2} \mathrm{Se}$ gas environment.

The unexposed films are highly resistive due to the presence of stearic acid in the P3HT matrix. Stearic acid hinders efficient electrons movement. However, exposure of the thin film to $\mathrm{H}_{2} \mathrm{~S}$ or $\mathrm{H}_{2} \mathrm{Se}$ gas, causing nanoparticles to nucleate in between P3HT layers. These nanoparticles facilitate the flow of electron, thus lowering the spectral density of noise. The high noise fluctuation for NP-CdS:P3HT thin film indicates that there could be an aggregation of the charges resulting in more substantial resistance at high frequency [21].

(b)

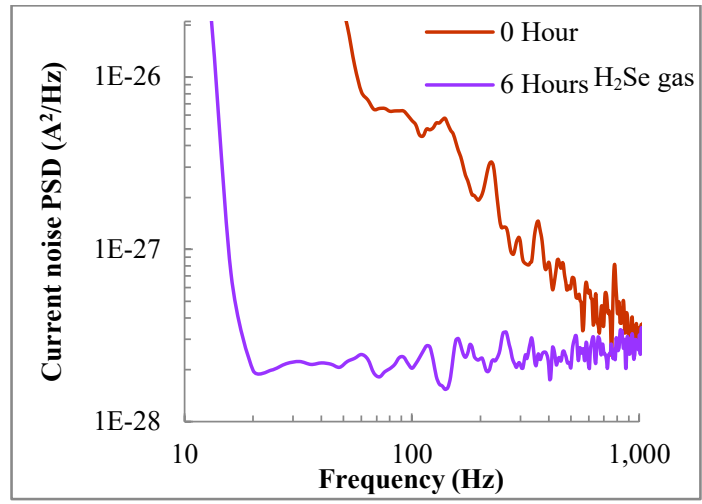

(d)

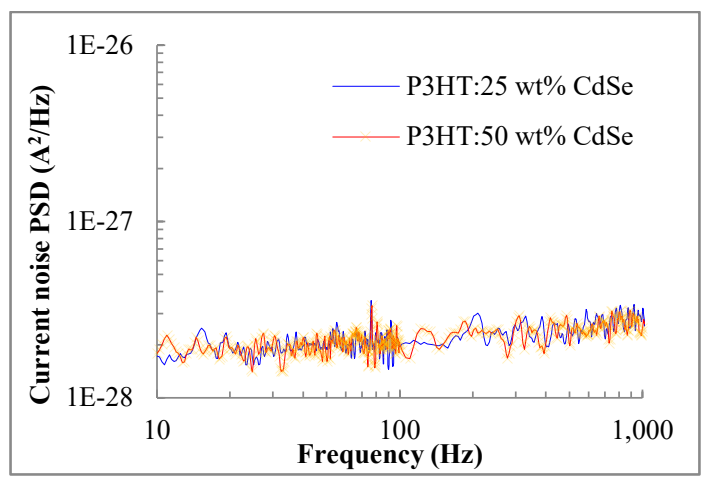

Figure 1: Johnson noise current spectral density of (a) NP-CdS:P3HT (b) NP-CdSe:P3HT (c) QD-CdS:P3HT (d) QD-CdSe:P3HT 
On the other hand, as shown in Figure 1 (c) and (d), QDCdX:P3HT has lower Johnson noise as compared with NPCdX:P3HT thin films. Among the benefits of thin films formed by directly combining quantum dots with P3HT is that both elements are an exceptional conductor. Therefore the noise for this device is substantially low and stable irrespective of the amount or types of quantum dots. Nonetheless, QD-CdX:P3HT thin films display a growing increase in noise spectra at a frequency greater than 100 $\mathrm{Hz}$, suggests that the thin film is prone to high-frequency degradation.

The noise results were supported by current density-voltage ( $J$ $V)$ measurement. The electrical properties studied were opencircuit voltage $\left(V_{\mathrm{oc}}\right)$, short-circuit current density $\left(J_{\mathrm{sc}}\right)$, fill factor (FF), and maximum power output $\left(P_{\max }\right)$. The fourth quadrant of $J-V$ graphs for NP-CdX:P3HT thin films under illumination were plotted in Figure 2. Excitons are created when incident photons are absorbed in thin films. Then, the excitons dispersed inside the polymer matrix until they reached the interface between polymer/nanoparticles and disassociated into electrons and holes [22]. Consequently, the electric field formed at the boundary layer, pushing electrons and holes to the opposite sides. The nanoparticle's HOMO and LUMO energy is relatively lower than P3HT. The electrons will then be transported to the cathode while the holes are transferred to the anode, producing photocurrent [23].

The thin films exposed to the gas environment demonstrated greater $J_{\mathrm{sc}}$ as compared to film not treated with gas. When no current is supplied or $J=0 \mathrm{~A}, V_{\text {oc }}$ can be determined. Figure 2 demonstrated that the value of $V_{\text {oc }}$ for the exposed films was twice as large as compared with unexposed thin films. NP-CdSe:P3HT gives the highest $V_{\mathrm{oc}}, 0.72 \mathrm{~V}$, while the other films are in the range of $0.2-0.6 \mathrm{~V}$. Even the principle of $V_{\text {oc }}$ is not yell well known, Brabec et al. suggest that it depends heavily on the ionization potential of the donor and the electron affinity of the acceptor; hence the amount energy offset [24]. Meanwhile, Qi et al. show $V_{\mathrm{oc}}$ is determined by the composition of the elementals' mixture even it is not a straightforward relationship [25]. Thus it justifies the low $V_{\text {oc }}$ value for thin films before gas treatment due to underdeveloped nanoparticles nucleation in the film matrices.

Short-circuit current density, $J_{\text {sc }}$, occurs when the current flow through the external circuit without connecting to a voltage source, $V=0 \mathrm{~V}$. Low $J_{\text {sc }}$ value for entire samples imply limited photon

absorption by the films. Transportation of the charge is associated with Fill Factor or FF. High charge mobility is desired to prevent significant losses due to recombination [26, 27]. However, calculation shows FF values are small for all samples indicating the considerable recombination level occurs in thin films. The results are as corroborated by low $J_{\text {sc }}$ value. The "squareness" of the FF is contributed by maximum power output, $P_{\max }$, that is when the current and the voltage of the device are at maxima, or:

$$
P_{\max }=J_{\mathrm{MPP}} \times V_{\mathrm{MPP}}
$$

where $V_{\mathrm{MPP}}$ and $J_{\mathrm{MPP}}$ are the values of voltage and current density at the maximum power point (MPP). Electronic devices must be operated at the maximum power point to generate maximum energy efficiency and minimize losses. In order to achieve maximum energy performance and, at the same time, reduces losses, the electronic appliances are desired to be operated at the highest power point [28].

The exposure of $\mathrm{H}_{2} \mathrm{~S}$ or $\mathrm{H}_{2} \mathrm{Se}$ gas nucleated approximately $9 \%$ of nanoparticles. Hence the improvements in $P_{\max }$ for the exposed film were insignificant. Thin films mixed with $50 \mathrm{wt} \%$ quantum dots, however, posses even smaller $P_{\max }$ value. This is contrary to the study by Lek et al. that reports a rise in the weight ratio of nanoparticles would improve electrical performance [29]. Nonetheless, the improvement can only be observed until a certain weight percentage is reached. Whilst the study shows a low amount of quantum dots or nanoparticles causes inefficient pathways for electrons transportation [30], too high nanomaterials loading causing limited mobility of the holes, leading to lower device's performance. The summary of the $J-V$ analysis is as tabulated in Table 1 . The overall results demonstrated that NPCdSe:P3HT nanocomposite the most reliable performance in both Johnson noise and $\mathrm{J}-\mathrm{V}$ evaluation of all thin films.

Table 1: The electrical properties of thin films from $J-V$ measurement

\begin{tabular}{lcccc}
\hline & $\boldsymbol{V}_{\text {oc }}(\mathrm{V})$ & $\begin{array}{c}\boldsymbol{J}_{\text {sc }} \\
\left(\mathbf{m A} / \mathbf{c m}^{2}\right)\end{array}$ & FF & $\begin{array}{c}\boldsymbol{P}_{\max } \\
(\mathbf{m W})\end{array}$ \\
\hline NP-CdS:P3HT & 0.2 & $1.2 \times 10^{-3}$ & 0.18 & $1.2 \times 10^{-4}$ \\
NP-CdSe:P3HT & 0.72 & $1.2 \times 10^{-3}$ & 0.15 & $1.3 \times 10^{-4}$ \\
QD-CdS:P3HT & 0.32 & $1.1 \times 10^{-4}$ & 0.14 & $4.8 \times 10^{-6}$ \\
QD-CdSe:P3HT & 0.2 & $7.5 \times 10^{-5}$ & 0.21 & $3.2 \times 10^{-6}$ \\
\hline
\end{tabular}

(a)

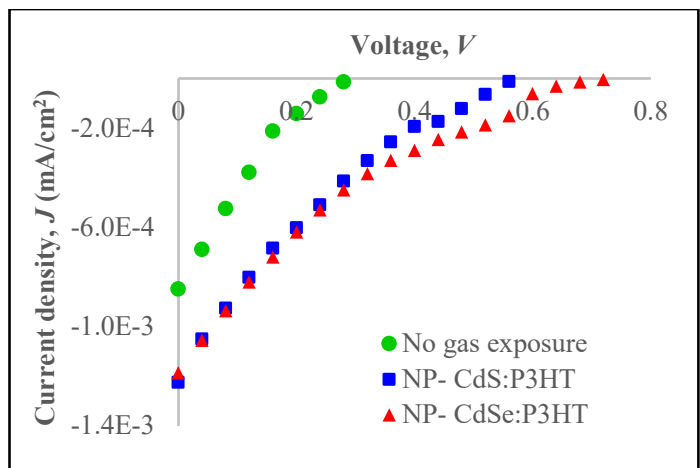

(b)

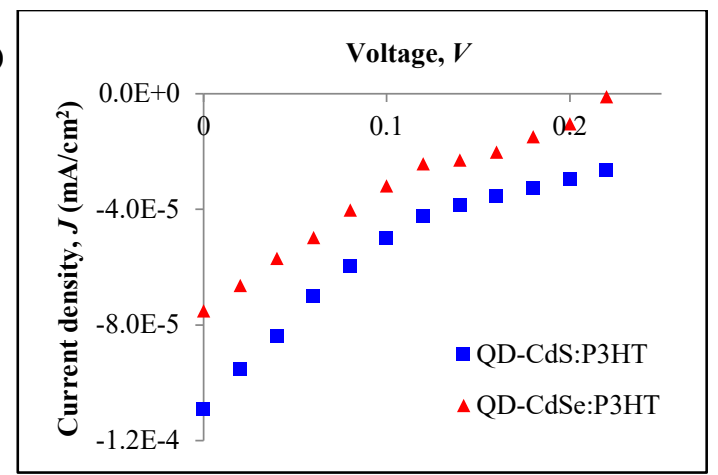

Figure 2: $J$ - $V$ graphs for thin films (a) unexposed sample, sample exposed to $\mathrm{H}_{2} \mathrm{~S}$ gas (NP- CdS:P3HT) and $\mathrm{H}_{2} \mathrm{Se}$ gas $(\mathrm{NP}-\mathrm{CdSe}: \mathrm{P} 3 \mathrm{HT})$, and (b) QD-CdS:P3HT and QD-CdSe:P3HT 
Figure 3 (a) displays the absorption spectra of pristine P3HT thin film, thin films before gas exposure, and after exposure to $\mathrm{H}_{2} \mathrm{~S}$ gas and $\mathrm{H}_{2} \mathrm{Se}$ gas. Conjugation system in $\mathrm{P} 3 \mathrm{HT}$ causes two peaks at 522 and $556 \mathrm{~nm}$ and a shoulder at $605 \mathrm{~nm}$ to appear in the UVVis graph. A similar result has been obtained by the Liao research group [31]. The peaks attribute to $\pi-\pi^{*}$ transition or the order of intermolecular chains of the polymer, while the shoulder is due to crystallization of polymer [32,33]. When P3HT were mixed with stearic acid, the absorption spectra are lower than that of pristine P3HT, and its peak shifted towards the red spectrum at 529 and $560 \mathrm{~nm}$, and the shoulder becoming less distinguishable. The shift indicates the presence of $\mathrm{Cd}^{2+}$ ion capped in the stearic acid matrices, as well as reduced P3HT $\pi$-conjugation length.

Before the thin films were exposed to the gas, the observable peak is at $560 \mathrm{~nm}$. Nonetheless, exposure to $\mathrm{H}_{2} \mathrm{~S}$ gas environment for 6 hours caused the peak to shift to $556.5 \mathrm{~nm}$. The blue shift of the peaks inkling the quantum confinement effect due to CdS nanoparticles formation in the thin film $[34,35]$. The shoulder at $605 \mathrm{~nm}$ is more perceptible compared with an unexposed thin film. This shoulder is usually due to an increased crystallization of intrachain interactions. The exposure to $\mathrm{H}_{2} \mathrm{~S}$ gas causing the absorption intensity to become lesser. This is due to the reaction of cadmium stearate with $\mathrm{H}_{2} \mathrm{~S}$ gas:

$$
\begin{gathered}
\left(\mathrm{CH}_{3}\left(\mathrm{CH}_{12}\right)_{16} \mathrm{COO}\right)_{2} \mathrm{Cd}+\mathrm{H}_{2} \mathrm{~S} \rightarrow \\
2 \mathrm{H}\left(\mathrm{CH}_{3}\left(\mathrm{CH}_{12}\right)_{16} \mathrm{COO}\right)+\mathrm{CdS}
\end{gathered}
$$

Similar to $\mathrm{H}_{2} \mathrm{~S}$ gas exposure, the absorption intensity of thin films exposed to $\mathrm{H}_{2} \mathrm{Se}$ gas ambiance decreased compared with the unexposed thin film. One possible reason that contributes to such a profile is the shape and amount of CdSe nanoparticles created. The aspect ratio of CdSe nanoparticles is high, in which it resembles rod-like, and some of the nanoparticles agglomerate, creating a larger cluster.

Photoluminescence (PL) is a process of spontaneous light emission from the material under optical excitation. Ideally, the PL spectrum mirroring the image of the absorption spectrum, hence it clearly can be observed from Figure 3(b) the PL spectra resemble the UV-Vis absorption spectra. PL measurement is an indicator of excitons dissociation and its efficiency to transfer charge in the composite materials. The intensity of PL decreased when exposed to $\mathrm{H}_{2} \mathrm{~S}$ and $\mathrm{H}_{2} \mathrm{Se}$ gas. The gas exposure caused the peak shifted towards the blue region, from $720 \mathrm{~nm}$ to $718 \mathrm{~nm}$ and $714 \mathrm{~nm}$, respectively. The deviation suggested the reduction in P3HT aggregation, causing the PL to quench.

The occurrence of PL depends on the distance from the excitons formed to the donor/acceptor interface [36]. If the distance is lesser than the excitons' diffusion length, charge transfer to the nanoparticle is anticipated, hence the PL is quenched [37]. The more significant range caused recombination to take place. From literature, exciton diffusion length for $\mathrm{P} 3 \mathrm{HT}$ is around $8 \mathrm{~nm}$ [38]. However, FESEM images in Figure 3 (c) - (e) showed that the distance between nanoparticles was considerably large, ranging from 100 to $150 \mathrm{~nm}$. The number of nanoparticles impregnated in the thin film was small, causing the exciton that is further from the donor/acceptor interface to recombine before reaching the interface.

The UV-Vis spectra when the CdS / CdSe quantum dots were physically mixed into P3HT polymer as shown in Figure 4 (a) and (b). The absorption of pristine P3HT is comparable to the thin film with $25 \mathrm{wt} \% \mathrm{CdS}$ and CdSe QDs. However, for QD-CdS:P3HT, the absorption is lower when the amount of QDs is doubled. This may be due to a smaller amount of P3HT in the composite [39]. The peaks and shoulders remain at the same wavelength as pristine P3HT. The absence of the CdS QDs absorption band is likely due to the overlapping with the P3HT absorption. While at $50 \mathrm{wt} \%$ of CdSe, the absorption is higher, and the shoulder is less distinguishable. The peaks are poorly shifted to red, 524 and 557.5 $\mathrm{nm}$ indicating the polymer chains are less crystallized due to QDs added. Both QD-CdS:P3HT and QD-CdSe:P3HT show no significant in amplitude variation with the increment of QDs wt $\%$, comparable to the results reported for P3HT:CdSe TBPO-capped at different weight percentage [40].

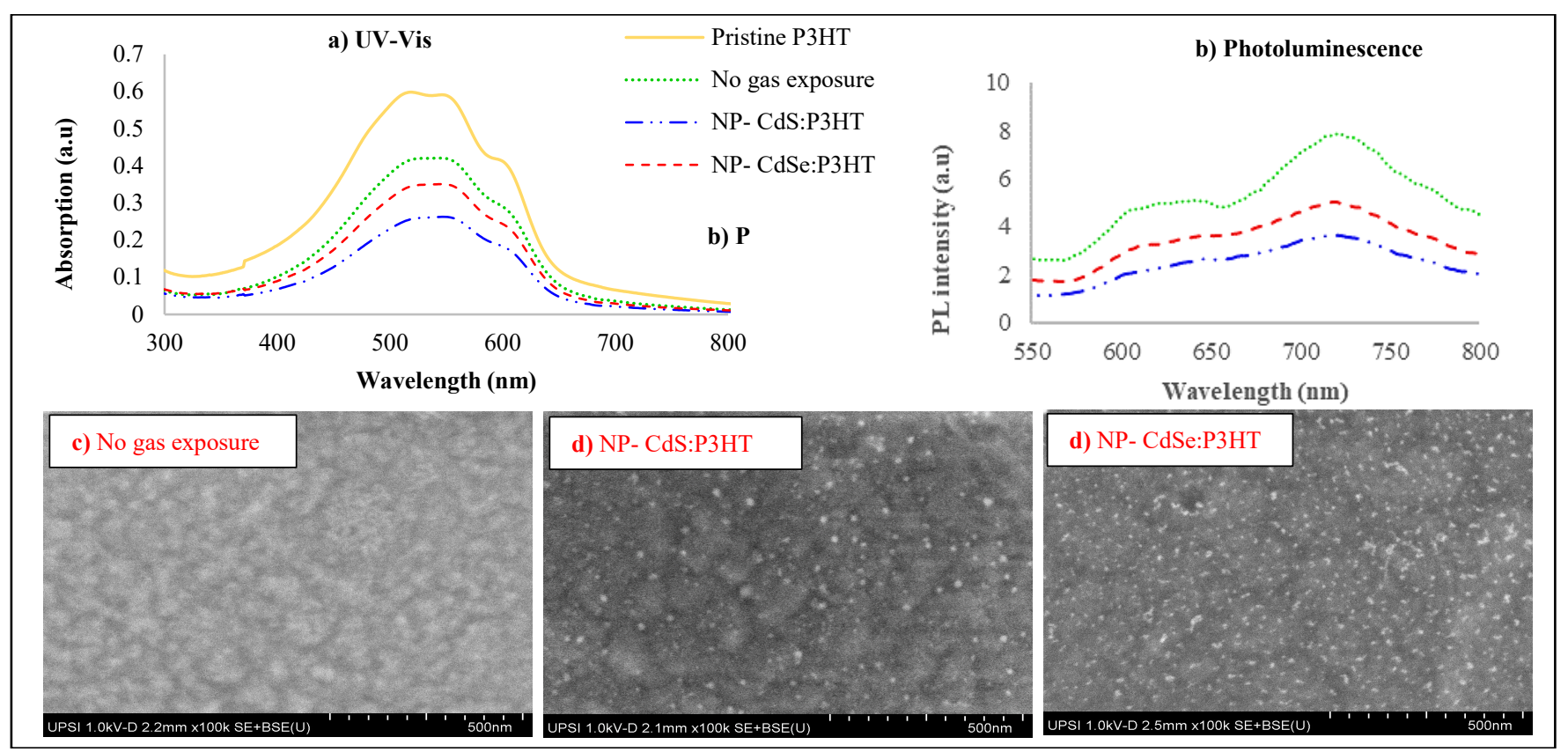

Figure 3: (a) UV-Vis absorption spectra, (b) photoluminescence spectra and (c) FESEM images for thin films not exposed to any gas, (d) exposed to $\mathrm{H}_{2} \mathrm{~S}$ gas (NP- CdS:P3HT), and (e) $\mathrm{H}_{2} \mathrm{Se}$ gas (NP-CdSe:P3HT) 

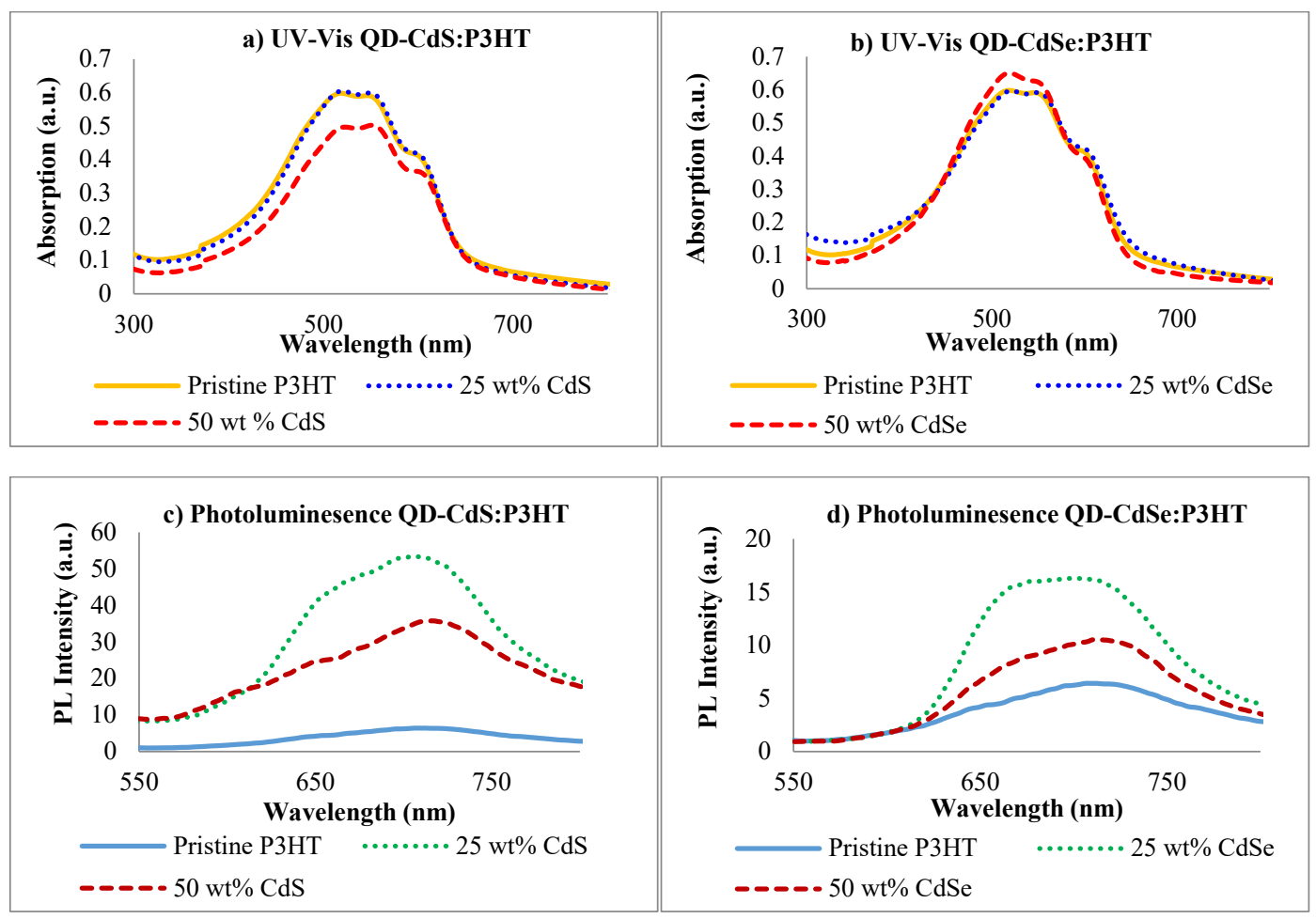

Figure 4: UV-Vis absorption spectra and photoluminescence of QD-CdS:P3HT and QD-CdSe:P3HT

On the other hand, photoluminescence spectra for QDCdS:P3HT and QD-CdSe:P3HT are shown in Figure 4 (c) and (d), respectively. Both types of thin-film displayed similar characteristics, in which a higher amount of QDs (50 wt\%) mixed into P3HT cause the film to quench stronger as compared to films with $25 \mathrm{wt} \%$ QDs. The quenching indicates a reduction in the domain size of P3HT blended with nanoparticles [41]. The decrease is owing to a shorter distance for the excitons to travel to the donor/acceptor interface when the weight percentage of nanoparticles in the polymer is doubled. The PL quenching also possibly due to the $\pi-\pi$ interaction of P3HT with the nanoparticles [42], creating a new decaying pathway for excitons [43]. Higher excitons dissociation can be justified for better device performance.

Nonetheless, the PL intensity of P3HT:CdS QDs is higher and has a narrower peak than that of P3HT:CdSe QDs. The P3HT:25 $\mathrm{wt} \% \mathrm{CdS}$ has a maximum at $704 \mathrm{~nm}$, while for P3HT:50 wt $\% \mathrm{CdS}$, the peak shifted to longer wavelength, $713.5 \mathrm{~nm}$. The shift is also known as Stokes-shift. The redshift implies the increment in polymer aggregation, which can be achieved by the incorporation of QDs into the polymer matrix, as have also been observed by others [44].

\section{Conclusion}

The analysis has been done on the nanocomposite thin films prepared via two approaches - direct impregnation of nanoparticles in P3HT matrix (in-situ), and by physically mixing quantum dots with P3HT (ex-situ). Results show that QDCdX:P3HT thin films possess low Johnson noise due to intrinsic properties of quantum dots and $\mathrm{P} 3 \mathrm{HT}$ as an excellent conductor. Consequently, the noise is considerably small and stable for this system regardless of the weight percentage or types of quantum dots. However, the increment of noise can be observed at a frequency above $100 \mathrm{~Hz}$ for QD:CdX-P3HT thin films. This signifies the thin film is vulnerable to high-frequency degradation. For nanocomposite produced through the in-situ technique, the presence of stearic acid the P3HT matrix curb the free flow of electrons movement.

It can be concluded NP-CdSe:P3HT nanocomposite displayed more reliable performance in both Johnson noise and $J-V$ measurement. Absorbance spectra show higher polymer crystallization NP-CdX:P3HT. The quantum confinement effect due to nanoparticles formation is translated by the shift of peaks and depreciation of absorption intensity. The PL intensity decreased when exposed to the gas. Both the thin films fabricated ex-situ displays similar spectra profile even when the amount of quantum dots was doubled. While the amount of quantum dots did not affect the absorbance significantly, the PL intensity decreased with increment of quantum dots' weight percentage. Overall, NPCdX:P3HT showed better performance compared to QD:CdXP3HT nanocomposite. Such findings have provided a bright prospective to study the nucleation of nanoparticles through gas exposure technique for optoelectronics applications.

\section{Conflict of Interest}

The authors declare no conflict of interest.

\section{Acknowledgment}

Authors are grateful to Universiti Putra Malaysia for the financial support through IPM Putra research grant 9674000.

\section{References}

[1] R. E. Gorga, R. E. Cohen, "Toughness Enhancements in Poly(Methyl Methacrylate) by Addition of Oriented Multiwall Carbon Nanotube" 
J.Polym.Sci. Polym. Phys., 42(14), 2690-2702, 2004. https://doi.org/10.1002/polb.20126

[2] H. Darabi, Radio Frequency Integrated Circuits and Systems, Cambridge University Press, 2015.

[3] J. B. Johnson, "Thermal Agitation Of Electricity in Conductors" Phy. Rev., 32, 97-109, 1928. https://doi.org/10.1103/PhysRev.32.97

[4] H. Nyquist, "Thermal Agitation of Eelectric Charge in Conductors" Phy. Rev., 32, 110-113, 1928. https://doi.org/10.1103/PhysRev.32.110

[5] X. Zhang, D. Chen, "An Integrated Circuit Solution to Johnson Noise Thermometry Using Low-Cost and Fast CMOS Technology" IEEE Sens. J., 19(9), 3240-3251, 2019. https://doi.org/10.1109/JSEN.2019.2893241

[6] G. Vasilescu, Electronic Noise and Interfering Signals: Principles and Application, Springer-Verlag Berlin Heidelberg, 2005.

[7] L. K. J. Vandamme, "Noise as a Diagnostic Tool for Quality and Reliability of Electronic Devices," IEEE Trans. on Electron Dev., 41(11), 2176 - 2187, 1997. https://doi.org/10.1109/16.333839

[8] Z. Chobola, L. Hasse, Z. Růžička, "Measurement of Low Frequency Noise of Monocrystalline Silicon Solar Cells," in XVII IMEKO World Congress, Croatia, 2003.

[9] P. R. F. Rocha, H. L. Gomes, L. K. J. Vandamme, D. M. de Leeuw, S. C. J. Meskers, P. van de Weijer, "Low-frequency Noise as a Diagnostic Tool for OLED reliability," in $22^{\text {nd }}$ International Conf. on Noise and Fluctuations, 2013.

[10] A. Carbone, B. K. Kotowska, D. D. Kotowski, "Space-Charge- Limited Current Fluctuations in Organic Semiconductors" Phy. Rev. Lett., 95, 236601-236605, 2005. https://doi.org/10.1103/PhysRevLett.95.236601

[11] L. Ke, X. Y. Zhao, R. S. Kumar, S. J. Chua, "Low Frequency Optical Noise from Organic Light Emitting Diode" Solid-State Electron., 52(1), 7-10, 2008. https://doi.org/10.1016/j.sse.2007.07.004

[12] J. J. Luo, I. M. Daniel, "Characterization and Modelling of Mechanical Behaviour of Polymer/Clay Nanocomposites" Composites Science and Technology, 63(11) 1607-1616, 2003. https://doi.org/10.1016/S02663538(03)00060-5

[13] C. L. Wu, Q. Zhang, M. Z. Rong, K. Friedrich, "Tensile Performance Improvement of Low Nanoparticles Filled-Polypropylene Nanocomposites" Compos. Sci. Technol., 62(10-11), 1327-1340, 2003. https://doi.org/10.1016/S0266-3538(02)00079-9

[14] M. Haridas, S. Srivastava, J. K. Basu "Tunable Variation of Optical Properties of Polymer Capped Gold Nanoparticles" Eur. Phys. J. D, 49, 93-100, 2008. https://doi.org/10.1140/epjd/e2008-00135-x

[15] Hung-Chou Liao, San-Yuan Chen, and Dean-Mo Liu. "In-Situ Growing CdS Single-Crystal Nanorods via P3HT Polymer as a Soft Template for Enhancing Photovoltaic Performance" Macromol. 42(17), 6558-6563, 2009. https://doi.org/10.1021/ma900924y

[16] H. Hoppe, "Nanomorphology - efficiency Relationship in Organic Bulk Heterojunction Plastic Solar Cells," Ph.D Thesis, Johannes Kepler University Linz, 2004.

[17] J. Hou, X. Guo, Active Layer Materials for Organic Solar Cells. In W. C. H. Choy (Ed.), Organic solar cells: Materials and Device Physics, SpringerVerlag, 2012.

[18] H. Tang, F. Zhao, F. Zhang, "Investigation on an Optically-Controlled PhaseShifter Based Organic Semiconductor Poly-(3-hexylthiophene) (P3HT)" J. Phys. Conf. Ser., 276(1), 012092, 2011. https://doi.org/10.1088/17426596/276/1/012092

[19] E. O. Sako, H. Kondoh, I. Nakai, A. Nambu, T. Nakamura, T. Ohta, "Reactive Adsorption of Thiophene on $\mathrm{Au}(111)$ from Solution" Chem. Phys. Lett., 413(4-6), 267-71, 2005. https://doi.org/10.1016/j.cplett.2005.07.086

[20] Y. Zhou, M. Eck, M. Krüger, M. Organic-Inorganic Hybrid Solar Cells: State of The Art, Challenges and Perspectives. In L. A. Kosyachenko (Ed.), Solar Cells - New Aspects and Solutions. IntechOpen, 2011.

[21] F.H. Naning, "Surface Pressure-Area Isotherm, Optical And Electrical Properties Of P3HT/Nanoparticles Thin Films By Modified LangmuirBlodgett Technique" Ph.D Thesis, Universiti Pendidikan Sultan Idris, 2017.

[22] B. Kippelen, J. L. Bredas, "Organic Photovoltaics" Energy Environ. Sci., 2, 251-261, 2009. https://doi.org/10.1039/B812502N

[23] N. S. Sariciftci, L. Smilowitz, A. J. Heeger, F. Wudl, "Photoinduced Electron Transfer From a Conducting Polymer to Buckminsterfullerene," Science, 258(5087), 1474-1476, 1992. https://doi.org.10.1126/science.258.5087.1474

[24] C. J. Brabec, G. Zerza, G. Cerullo, S. De Silvestri, S. Luzzati, J. C. Hummelen, S. Sariciftci, "Tracing Photoinduced Electron Transfer Process in Conjugated Polymer/Fullerene Bulk Heterojunctions in Real Time" Chem. Phy. Lett., 340(3-4), 232-236, 2001. https://doi.org/10.1016/S0009-2614(01)00431-6

[25] B. Qi, Q. Zhou, J. Wang, "Exploring the Open-Circuit Voltage of Organic Solar Cells Under Low Temperature" Sci. Rep., 5, 11363, 2015. https://doi.org/10.1038/srep11363

[26] J. A. Bartelt, D. Lam, T. M. Burke, S. M. Sweetnam M. D. McGehee, "Charge-Carrier Mobility Requirements for Bulk Heterojunction Solar Cells with High Fill Factor and External Quantum Efficiency $>90 \%$ " Adv. Energy Mater., 5, 1500577, 2015. https://doi.org/10.1002/aenm.201500577
[27] I. Riedel, V. Dyakonov, "Influence Of Electronic Transport Properties of Polymer-Fullerene Blends on the Performance of Bulk Heterojunction Photovoltaic Devices" Phys. Status Solidi A, 201, 1332-1341, 2004. https://doi.org/10.1002/pssa.200404333

[28] D. Bartesaghi, I. D. Pérez, J. Kniepert, S. Roland, M. Turbiez, D.N. L. J. A. Koster, "Competition Between Recombination and Extraction of Free Charges Determines the Fill Factor of Organic Solar Cells" Nat. Commun., 6, 7083, 2015. https://doi.org/10.1038/ncomms8083

[29] J. Y. Lek, Y. M. Lam, J. Niziol, M. Marzec, "Understanding PolycarbazoleBased Polymer:CdSe Hybrid Solar Cells," Nanotechnology, 23(31), 315401, 2012. https://doi.org/10.1088/0957-4484/23/31/315401

[30] Y. Zhou, M. Eck, C. Men, F. Rauscher, P. Niyamakom, S. Yilmaz, ...M. Krüger, "Efficient Polymer Nanocrystal Hybrid Solar Cells by Improved Nanocrystal Composition," Sol. Mat. Sol. Cells, 95(12), 3227-3232, 2011. https://doi.org/10.1016/j.solmat.2011.07.015

[31] H. C. Liao, N. Chantarat, S. Y. Chen, C. H. Peng, "Annealing Effect on Photovoltaic Performance of Hybrid P3HT/In-Situ Grown CdS Nanocrystal Solar Cells" J. Electrochem. Soc., 158(7), 5251-5455, 2011. https://doi.org/10.1149/1.3585668

[32] U. Farva, M. A. Khan, C. Park, Effect of Post Annealing on the Performance of CdSe/P3HT Bulk Hetero-Junction Solar Cells. In Photovoltaic Specialist Conference, San Diego, USA, 2008.

[33] P. J. Brown, D. S. Thomas, A. Köhler, J. S. Kim, C. M. Ramsdale, H. Sirringhaus, R. H. Friend, "Effect of Interchain Interactions on the Absorption and Emission of Poly(3-hexylthiophene)" Phys. Rev. B, 67(6), 064203, 2003. https://doi.org/10.1103/PhysRevB. 67.064203

[34] R. R. Prabhu, M. A. Khadar, "Characterization of Chemically Synthesized CdS Nanoparticles" Pramana J. Phys., 65, 801-807, 2005 https://doi.org/10.1007/BF02704078

[35] P. Sonar, K. P. Sreenivasan, T. Madddanimath, K. Vijayamohanan, "Comparative Behavior of CdS and CdSe Quantum Dots in Poly(3hexylthiophene) Based Nanocomposites" Mater. Res. Bull., 41(1), 198-208, 2006. https://doi.org/10.1016/j.materresbull.2005.07.032

[36] B. Freisinger, "Investigation of P3HT/PCBM Particle-Based Solar Cells," Ph.D Thesis, Johannes Gutenberg-Universität Mainz, 2013.

[37] A. J. Ferguson, N. Kopidakis, S. E. Shaheen, G. Rumbles, "Quenching of Excitons by Holes in Poly(3-hexylthiophene) Films" J. Phys. Chem., 112(26), 9865- 9871, 2008. https://doi.org/10.1021/jp7113412

[38] B. Annalisa, D. L. Tiziana, B. Carmela, V. Fulvia, H. Saif, M. Carla, "Exciton Dynamics in Hybrid Polymer/QD Blends", Energy Procedia, 44, 167-175, 2014. https://doi.org/10.1016/j.egypro.2013.12.024.

[39] P. E. Shaw, A. Rusecka, I. D. W. Samuel, "Exciton Diffusion Measurements in Poly(3-hexylthiophene)" Adv. Mater. 20(18), 3516-3520, 2008 https://doi.org/10.1002/adma.200800982

[40] D. Loubiri, Z. Ben Hamed, S. Ilahi, M. A. Sanhoury, F. Kouki, N. Yacoubi, "Effect of TBPO-Capped CdSe Nanoparticles Concentration on SubBandgap Absorption in Poly(3-hexylthiophene) Thin Films Studied by Photothermal Deflection Spectroscopy" Synth. Met, 206, 1-7, 2015. https://doi.org/10.1016/j.synthmet.2015.04.018.

[41] A. J. MacLachlan, T. Rath, U. B. Cappel, S. A. Dowland, H. Amenitsch, A. C. Knall, ... S. A. Haque, "Polymer/Nanocrystal Hybrid Solar Cells: Influence of Molecular Precursor Design on Film Nanomorphology, Charge Generation and Device Performance" Adv. Funct. Mater., 25, 409-420, 2015. https://doi.org/10.1002/adfm.201403108

[42] H. C. Liao, S. Y. Chen, D. M. Liu, "In-Situ Growing CdS Single-Crystal Nanorods via P3HT Polymer as a Soft Template for Enhancing Photovoltaic Performance" Macromolecules, 42(17), 6558-6563, 2009. https://doi.org/10.1021/ma900924y

[43] M. T. Khan, R. Bhargav, A. Kaur, S. K. Dhawan, S. Chand, "Effect of Cadmium Sulphide Quantum Dot Processing and Post Thermal Annealing on P3HT/PCBM Photovoltaic Device" Thin Solid Films, 519(3), 1007-1011, 2010. https://doi.org/10.1016/j.tsf. 2010.08.032.

[44] S. N. Sharma, T. Vats, N. Dhenadhayalan, P. Ramamurthy, A. K. Narula, "Ligand-Dependent Transient Absorption Studies of Hybrid Polymer:CdSe Quantum Dot Composites" Sol. Energy Mater. Sol., 100, 6-15, 2012. https://doi.org/10.1016/j.solmat.2011.10.020 